\title{
Gérard LÉVESQUE, La laïcité en harmonie avec la liberté
} religieuse

Montréal, Liber, 2019

Philippe Ségur

\section{CpenEdition}

\section{Journals}

Édition électronique

URL : https://journals.openedition.org/rdr/1363

DOI : $10.4000 /$ rdr.1363

ISSN : 2534-7462

Éditeur

Presses universitaires de Strasbourg

Édition imprimée

Date de publication : 16 novembre 2020

Pagination : 215-217

ISBN : 979-10-344-0073-7

ISSN : 2493-8637

\section{Référence électronique}

Philippe Ségur, "Gérard LÉvesque, La laïcité en harmonie avec la liberté religieuse », Revue du droit des religions [En ligne], 10 | 2020, mis en ligne le 16 novembre 2020, consulté le 04 mai 2022. URL : http:// journals.openedition.org/rdr/1363; DOI : https://doi.org/10.4000/rdr.1363

Ce document a été généré automatiquement le 4 mai 2022.

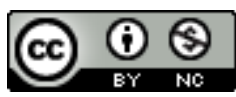

La revue du droit des religions est mise à disposition selon les termes de la Creative Commons Attribution - Pas d'Utilisation Commerciale 4.0 International - CC BY-NC 4.0. 


\title{
Gérard LÉVESQUE, La laïcité en harmonie avec la liberté religieuse
}

Montréal, Liber, 2019

\author{
Philippe Ségur
}

\section{RÉFÉRENCE}

Gérard LÉVESQUE, La laïcité en harmonie avec la liberté religieuse, Montréal, Liber, 2019, $204 \mathrm{p}$.

1 Cet essai se donne pour but de réévaluer le «climat de permissivité » en matière de religion dans le contexte de la laïcité québécoise. Le Canada n'échappe pas, en effet, aux revendications des identités religieuses qui conduisent à des exigences spécifiques en matière d'alimentation scolaire, de ségrégation des sexes et plus largement en matière d'expression des croyances dans l'espace public. Cette situation qui invite à la tolérance comme entorse à un principe juridique se complique d'une notion particulière au droit canadien, celle d'accommodement raisonnable. Or, l'accommodement - qui permet un tempérament de nature religieuse à l'ordre juridique - n'est pas une obligation légale, ni un droit, et son refus demeure discrétionnaire (p. 126 et s.). Sur ce point comme sur les débats qui agitent aujourd'hui la société québécoise, le lecteur trouvera dans cet ouvrage des pages argumentées et inspirées par un souci de faire pièce à «l'expansionnisme religieux ». À cet égard, l'harmonisation que l'auteur appelle de ses vœux pourra apparaître comme une sanctuarisation d'une laïcité supposée « impartiale et équitable » dans l'espace de la gouvernementalité au sens foucaldien du terme, tandis que le soin de décider d'éventuels accommodements religieux serait retiré aux juges pourtant défenseurs naturels des libertés individuelles, comme on sait, dans un système de common law.

2 Pour parvenir à cette proposition, la discussion se situe sur le terrain d'une complémentarité du droit naturel et du droit positif. Ainsi, « en tant qu'être doué d'une dimension spirituelle, l'être humain a le droit de croire en la transcendance, au divin et 
de manifester ses croyances» (p. 32-33). Nul besoin ici d'entrer dans le débat sur la question de savoir si une aptitude (la spiritualité) peut fonder un droit naturel (la liberté de religion) dont l'auteur infère un droit positif complémentaire (le droit de culte). Il s'agit là d'un parti pris philosophique, d'ailleurs restreint dans ce livre au champ de la transcendance, qui exclut la question de l'autonomie du sujet, c'est-à-dire l'apport des sciences cognitives et de l'anthropologie du mythe. Or, celles-ci relativisent de beaucoup l'idée de liberté, a fortiori celle de liberté religieuse qui, comme droit naturel, ne va pas nécessairement de soi.

3 Reprenant les définitions de la religion formulées par la Cour suprême du Canada en 1985 (R. c. Big M Drug Mart Ltd) et en 2004 (Syndicat Northcrest c. Amselem), l'ouvrage interroge les thèmes de l'interdiction du port des signes religieux par les agents de l'État et du port du voile islamique à l'aune d'une laïcité comprise comme recherche du bien commun et par là irréductible « à la satisfaction d'un seul besoin individuel de la personne singulière » (p. 99). Or, la compréhension de ce désir individuel, issu d'une liberté présentée comme naturelle, n'est pas sans intérêt. Selon l'auteur, la conciliation possible entre laïcité et liberté religieuse résiderait dans le libre choix individuel qui implique que la plupart de nos actions volontaires soient mixtes, c'est-à-dire fondées sur un ordre de priorité délibéré entre ce que nous voulons et ce que nous ne voulons pas. Ainsi lorsque les sikhs, confrontés au choix de déposer leur kirpan pour accéder et se faire entendre au Parlement canadien ou de le garder et de s'en voir refuser l'entrée, ont préféré respecter leur prescription religieuse, ils auraient témoigné « une liberté religieuse respectueuse de l'autonomie de l'État et de la laïcité " (p. 106). De même, des femmes musulmanes pourraient-elles librement choisir de délaisser le voile afin d'entrer dans la fonction publique québécoise pour ne pas nuire à leur carrière professionnelle.

4 Si l'on peut souscrire à cette position au nom du bon sens, il est toutefois permis d'en discuter les prémisses comme les conséquences sur un plan philosophique et politique. Le déterminisme spinoziste serait, par exemple, utile pour montrer à quel point la notion de libre arbitre masque l'ignorance des causes efficientes qui, au-delà des causes finales, déterminent réellement l'individu (Éthique, I, Appendice). L'inclination des sikhs ou des femmes musulmanes en faveur de l'une ou l'autre des deux branches de l'alternative ne devrait pas alors s'analyser en fonction de l'idée de libre arbitre, mais d'un rapport de puissance: celui de l'État qui fixe les termes du choix. Comme l'a montré Robert Dahl, un choix impliquant des pertes sévères pour qui refuse de se conformer est, par nature, coercitif (Modern Political Analysis, 1963). Dès lors, c'est seulement en prenant en compte ce rapport de domination et en réexaminant la légitimité de l'État à définir le bien commun et les fondements sur lesquels il le fait, que la question de l'harmonisation de la liberté religieuse et de la laïcité pourrait, sans équivoque, être tranchée. 


\section{AUTEURS}

PHILIPPE SÉGUR

Professeur de droit public, Université de Perpignan Via Domitia, Centre du droit économique et du développement (CDED) 